ScIDice

\section{Evaluation Of Commonly Treated Mandibular Teeth With Preventive Resin Restoration Among Children With Mixed Dentition}

Sarojini $\mathrm{K}^{1}$, Vignesh Ravindran ${ }^{2 *}$

${ }^{1}$ Saveetha Dental College and Hospitals, Saveetha Institute of Medical and Technical Sciences (SIMATS), Saveetha University, Chennai- 77, India. ${ }^{2}$ Senior Lecturer, Department of Pediatric and Preventive Dentistry, Saveetha Dental College and Hospitals, Saveetha Institute of Medical and Technical Sciences [SIMATS], Saveetha University, Chennai- 77, India.

\title{
Abstract
}

Background: Dental caries is recognised to be the most prevalent infectious disease globally. It affects all age groups and most commonly children between 6-12 year old involving both primary and permanent teeth. Apart from conventional measures for the management of dental caries, preventive measures involving sealing of the cavitated and non cavitated pits and fissures can be a feasible method for cost-effectiveness in the prevention of caries. Among the newer techniques with a long-term success rate for preventing caries are preventive resin restoration (PRR).

Aim: This study aims to evaluate the most commonly treated mandibular teeth with preventive resin restoration in children with mixed dentition.

Materials and Methods: This retrospective study was conducted in a university setting. Data were collected from 980 children between the ages of 6-12years who underwent preventive resin restoration for primary or permanent teeth have been included in the study. The extracted data was tabulated in a spreadsheet (Excel 2017: Microsoft Office) and analysed using SPSS 23 version software (SPSS, Inc., Chicago). Descriptive statistics and chi-square tests were performed with the level of significance at $5 \%(\mathrm{P}<0.05)$.

Results: Most PRR was done in 6 years old male patients $14.88 \%$ followed by 10 years $10.23 \%$ and 8 years $9.30 \%$ female patients respectively. Both permanent mandibular first molars are highly treated with PRR in which permanent left mandibular first molar is more commonly treated for males $16.28 \%$ than females $15.35 \%$ and permanent right mandibular first molar is more commonly treated for females $16.28 \%$ than males $10.70 \%$ This was found to be a statistically significant $(\mathrm{P}$ value $=$ $0.029)$.

Conclusion: Within the limitations of our study it can be concluded that, preventive resin restoration is more commonly used for permanent right and left first molar region for caries prevention in both primary and permanent teeth in children between 6 - 12 years of age.

Keywords: Dental Caries; Mandibular Molars; Mixed Dentition; Preventive Resin Restoration; Innovative Method.

\section{Introduction}

Dental caries is recognised to be the most prevalent infectious disease globally [1]. It affects all age groups and most commonly children between 6-12 year old involving both primary and permanent teeth [2]. Dental caries is a multifactorial microbial infectious disease that is characterized by demineralization of the inorganic and destruction of the organic substance of the tooth resulting in cavitation [3]. The major key components in the ae- tiology of dental caries are; a) cariogenic microorganisms, b) fermentable carbohydrates, c) a defenceless tooth and host and d) time. Oral health is invariably a part of general health and improvement of oral health in children for the prevention of dental caries is integral [4]. The associated factors to this change in the pattern of oral health might be dietary changes, improved oral hygiene habits, proper utilization of fluorides, and other professional measures along with the school-based preventive programs [5]. In addition, awareness and knowledge on maintaining oral

\footnotetext{
*Corresponding Author:

Vignesh Ravindran,

Senior Lecturer, Department of Pediatric and Preventive Dentistry, Saveetha Dental College and Hospitals, Saveetha Institute of Medical and Technical Sciences [SIMATS], Saveetha

University, Chennai- 77, India.

Tel: +91-9789934476

E-mail: vigneshr.sdc@saveetha.com

Received: September 13, 2021

Accepted: September 21, 2021

Published: September 22, 202

Citation: Sarojini K, Vignesh Ravindran. Evaluation Of Commonly Treated Mandibular Teeth With Preventive Resin Restoration Among Children With Mixed Dentition. Int J Dentistry Oral Sci. 2021;8(9):4509-4513. doi: http://dx.doi.org/10.19070/2377-8075-21000917
}

Copyright: Vignesh Ravindran 2021 . This is an open-access article distributed under the terms of the Creative Commons Attribution License, which permits unrestricted use, distribution and reproduction in any medium, provided the original author and source are credited. 
health among children and parents will contribute a major role in preventing dental caries $[6,7]$. Considering these factors, caries appears to be a preventable and controllable disease $[8,9]$. The prevalence of caries in a population must be assessed at regular intervals to establish the spread and the necessity for preventive and restorative care.

Preventive dentistry employs procedures in the practice of dentistry and community health programmes that prevents the occurrence of oral diseases providing good oral health. Prevention at the initial level is a remarkable measure in dentistry, especially in the field of pediatric dentistry [10]. Since the utilization of preventive measures can prevent impending complications, dental professionals have a significant responsibility toward early screening providing preventive measures and treatment needs [11]. The significance of retaining the primary teeth in the oral cavity until physiological exfoliation occurs is necessary as they act as the space maintainer for permanent teeth and preserve the arch integrity. Mandibular molars are more susceptible to dental caries than maxillary molars which contribute to the early eruption and topographic anatomical configuration [12]. Early implementation of preventive dental care programs and clinical care management appear to be fundamental for all children to prevent costs for caries treatment.

An integral component of modern pediatric restorative dentistry is resin-based composite. They can be employed effectively for preventive resin restorations. As caries predominantly involves the occlusal surfaces of erupting molars and premolars and therefore accounts for almost $80-90 \%$ of pit and fissure caries in permanent teeth [13]. Apart from conventional measures for the management of dental caries, preventive measures involving sealing of the cavitated and non cavitated pits and fissures can be a feasible method for cost-effectiveness in the prevention of caries. Among the newer techniques with a long-term success rate for preventing caries are preventive resin restoration (PRR) [14]. A preventive resin restoration is a conservative and minimally invasive treatment that involves limited excavation to remove carious tissue, restoration of the excavated area with a composite resin, and application of a sealant over the surface of the restoration and remaining, sound, contiguous pits and fissures [15]. Preventive resin restoration is an alternative to the conventional technique in which, in addition to carious tissue, sound pits and fissures are prepared and an amalgam restoration is placed. A preventive resin restoration is suggested when the carious lesion in a pit or fissures, small and discrete. Hence it is used in premolars, primary molars and permanent molars. However, the placement of a resin is very technique sensitive, the poor placement techniques such as moisture contamination, improper sealing of all pits and fissures, inadequate etching, rinsing or drying, insufficient curing time which ultimately results in material wear as the reasons for failure [16]. Several studies have reported the success and minimal invasiveness of the preventive resin restoration as the treatment of choice for small, discrete lesions of the pits and fissures [17]. Our team has extensive knowledge and research experience that has translate into high quality publications [18-30, 31-37]. With this background, this study aims to evaluate the most commonly treated mandibular teeth with preventive resin restoration in children with mixed dentition.

\section{Materials and Methods}

This retrospective study was conducted in a university setting. A total of 535951 treatment records were assessed for the study. Simple random sampling was done to minimise the sampling bias. Data were collected from 980 children with mixed dentition who underwent preventive resin restoration for primary or permanent teeth based on the inclusion and exclusion criteria. The data collection and analysis was done by two examiners. The inclusion criteria were children between the ages of 6-12 years, children who underwent preventive resin restoration treatment for primary or permanent teeth and complete records of the patient and treatment done in the case sheet with photographic evidence. Exclusion criteria for the study were patients less than 6 and more than 12 years of age, incomplete case records and missing photographic proof of completed treatment. A third examiner reviewed the case records of the collected data to ascertain the validity of the data by ensuring the data with the post-operative photographs. The extracted data were tabulated in a spreadsheet (Excel 2017: Microsoft Office) and analysed using SPSS 23 version software (SPSS, Inc., Chicago). Descriptive statistics and chi-square tests were performed with the level of significance at $5 \%(\mathrm{P}<0.05)$.

\section{Results and Discussion}

In this study based on the inclusion and exclusion criteria around 980 dental treatment records were analyzed. Of which $52.56 \%$ were males and $47.44 \%$ were females. (Figure1) Most PRR was done in 6 years old male patients $14.88 \%$ followed by 10 years $10.23 \%$ and 8 years $9.30 \%$ female patients respectively (Figure 2 ). PRR is more commonly treated with permanent left first mandibular molars $31.63 \%$ and permanent right first mandibular molars $26.98 \%$ respectively (Figure 3). Both permanent mandibular first molars are highly treated with PRR in which permanent left mandibular first molar is more commonly treated for males $16.28 \%$ than females $15.35 \%$ and permanent right mandibular first molar is more commonly treated for females $16.28 \%$ than males $10.70 \%$ (Figure 4) Mandibular right quadrant is commonly treated for females $24.19 \%$ than males $21.4 \%$ respectively and the mandibular left quadrant is more commonly treated for males $31.16 \%$ than females $23.26 \%$ (Figure 5).

Dental caries persist as a major public health concern worldwide [38]. Recent studies have reported the prevalence of dental caries is high in children between the age of 6-12 years [39]. Most previous researchers have evaluated risk factors for dental caries in the mixed dentition cross-sectionally. Since the dental caries process takes time to develop into clinically detectable lesions, risk factors for dental caries should be analyzed by assessing factors that arise before and during the time of clinical caries detection [40]. Caries predominantly affects the occlusal surfaces of erupting molars and premolars and thus resulting in approximately $80-90 \%$ of pit and fissure caries in permanent teeth [41]. Apart from traditional measures for the management of dental caries, preventive measures incorporating sealing of the cavitated and non cavitated pits and fissures can be a feasible method for cost-effectiveness the prevention and management of caries. Management and prevention of pits and fissure caries have become a complex issue in this modern dentistry [42]. Controversies go on with the promising and most suitable method for treating those pits and fissures with or without caries. Preventive resin restoration (PRR) has been established to be such an effective means of treating pits and fissure 
Figure 1. This pie chart represents the gender of the patient who underwent PRR in mandibular teeth, 52.66\% were males and $47.44 \%$ were females.

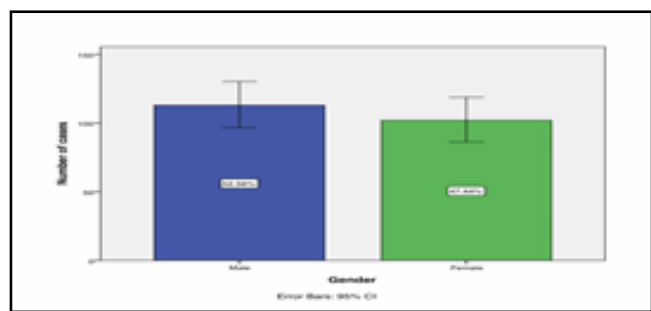

Figure 2. This bar graph represents the correlation between the age and the gender of the patient. The $\mathrm{X}$-axis represents the age of the patient and the Y-axis represents the gender of the patient. Blue colour denotes male patients and green colour denotes female patients. It shows that most PRR was done in 6 years old male patients $14.88 \%$ followed by 10 years

$10.23 \%$ and 8 years $9.30 \%$ female patients respectively. This was found to be a statistically significant $P$ value $=0.049$, $P=<0.05$.

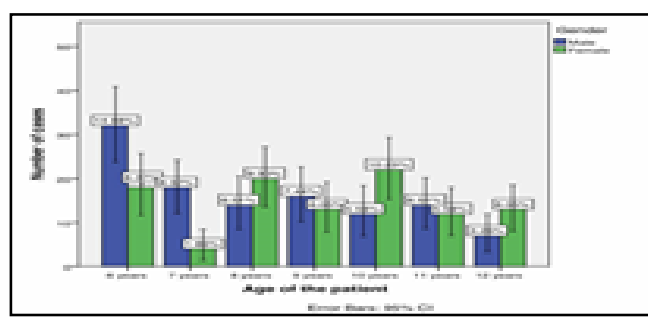

Figure 3. This bar chart shows the most commonly treated mandibular teeth with PRR in children with mixed dentition. It shows PRR is more commonly treated with permanent left first mandibular molars $31.63 \%$ and permanent right first mandibular molars $26.98 \%$ respectively.

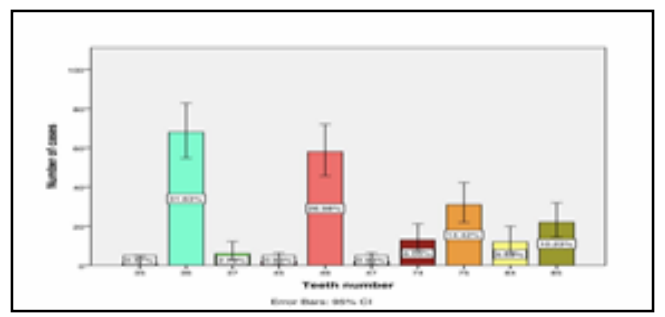

Figure 4. This bar graph shows the correlation between mandibular teeth treated with PRR and the gender of the patient. The X-axis represents the mandibular teeth treated with PRR and the Y-axis represents the gender of the patient. Blue colour denotes male patients and green colour denotes female patients. It indicates that both permanent mandibular first molars are highly treated with PRR in which permanent left mandibular first molar is more commonly treated for males $16.28 \%$ than females $15.35 \%$ and permanent right mandibular first molar is more commonly treated for females $16.28 \%$ than males $10.70 \%$ This was found to be a statistically significant $P$ value $=0.029, P=<0.05$.

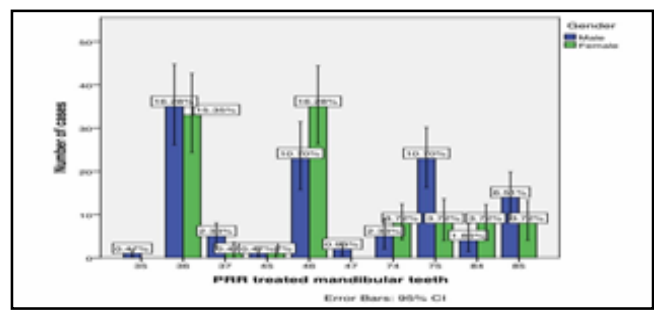

Figure 5. This bar graph shows the correlation between the quadrant of the mandibular teeth treated with PRR and the gender of the patient. The $\mathrm{X}$-axis represents the quadrant of the mandibular teeth treated with PRR and the Y-axis represents the gender of the patient. Blue colour denotes male patients and green colour denotes female patients. It indicates that the mandibular right quadrant is commonly treated for females $24.19 \%$ than males $21.4 \%$ respectively and the mandibular left quadrant is more commonly treated for males $31.16 \%$ than females $23.26 \%$. This was found to be a statistically insignificant $\mathrm{P}$-value $=0.085, \mathrm{P}=>0.05$.

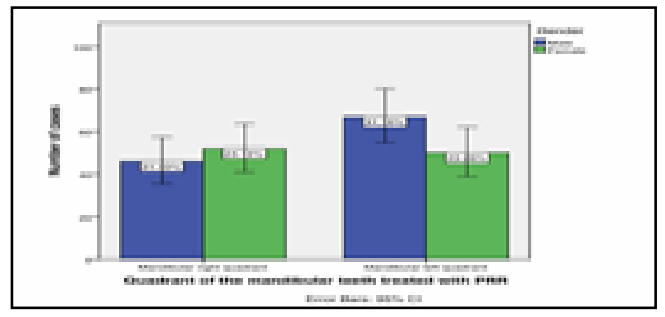


caries. Preventive resin restoration is a conservative and minimally invasive treatment that involves limited excavation to remove carious tissue, restoration of the excavated area with a composite resin, and application of a sealant over the surface of the restoration and remaining sound, contiguous pits and fissures [43].

In our studies, most PRR was done in 6 years old male patients $14.88 \%$ followed by 10 years $10.23 \%$ and 8 years $9.30 \%$ female patients respectively. A similar observation of higher caries prevalence among children with mixed dentition have been documented. The caries prevalence rate of about $63.20 \%$ between $6-10$ years has been observed in a previous study the higher occurrence of dental caries in preschool children may be associated with dietary changes [44]. Many studies have reported a significant association between the frequency of sugar intake and dental caries [45]. Our study observed the most commonly treated mandibular teeth with PRR in children with mixed dentition. It shows PRR is more commonly treated with permanent left first mandibular molars $31.63 \%$ and permanent right first mandibular molars $26.98 \%$ respectively. A similar study assessed and confirmed that occlusal fissures on the first and second molars contributed most significantly to caries frequency, from $52.7 \%$ to $66.3 \%$ [46]. Another study also observed that mandibular molars were most susceptible to caries. Earlier research has also shown that the most CARR was done in primary mandibular molars followed by permanent mandibular molars [47]. The higher caries susceptibility in the mandibular arch could be due to the fissure topography of molars. Studies stated that the reason for this phenomenon could be a combination of complicated surface morphology and difficult access for significant oral hygiene [48]. Soon after an eruption, a majority of the fissures of occlusal surfaces in molars show early signs of caries [49].

Our study indicated that both permanent mandibular first molars are highly treated with PRR in which permanent left mandibular first molar is more commonly treated for males $16.28 \%$ than females $15.35 \%$ and permanent right mandibular first molar is more commonly treated for females $16.28 \%$ than males $10.70 \%$. Our study also reported that the mandibular right quadrant is commonly treated for females $24.19 \%$ than males $21.4 \%$ respectively and the mandibular left quadrant is more commonly treated for males $31.16 \%$ than females $23.26 \%$. A previous study evaluated the caries prevalence and found that females (59.1\%) showed a higher incidence of caries than males (40.9\%)[50]. On the contrary, one study reported that gender and age do not affect the prevalence of caries on teeth sites [51]. Caries appear to be a preventable and controllable disease. The prevalence of caries in a population must be assessed at regular intervals to establish the spread and the necessity for preventive and restorative care.

There are few limitations for this study, such as minimum external validity and hence the validity can be extended by encompassing subjects of a wider range. The study is retrospective and does not record the success of PRR. The future scope for this study involves the identification of that section of the population where prophylactic management is a necessity and creates the need for PRR.

\section{Conclusion}

Within the limitations of our study, it can be concluded that pre- ventive resin restoration is more commonly used for permanent right and left the first molar region for caries prevention in both primary and permanent teeth in children between $6-12$ years of age. This could be related to the higher caries susceptibility in the mandibular arch due to the fissure topography of molars. In addition, more caries is experienced in younger age groups, and their incidence decreases as age increases. However this study has not evaluated the success rate, further research will focus on the success rate of PRR

\section{Acknowledgement}

The authors are thankful to the Department of Paediatric dentistry, Saveetha dental college, Saveetha Institute of Medical and Technical Sciences, Saveetha University for providing a platform to express our knowledge.

\section{Source of Funding}

This present study was supported by

- Saveetha dental college

- Saveetha Institute of Medical and Technical Sciences

- Saveetha university

- Kanagaraj Stores.

\section{References}

[1]. Dye BA, Hsu KL, Afful J. Prevalence and measurement of dental caries in young children. Pediatr Dent. 2015 May 15;37(3):200-16.

[2]. Al-Badr AH, AlJameel AH, Halawany HS, Al-Jazairy YH, Alhadlaq MK, AlMaflehi NS, et al. Dental caries prevalence among Type 1 diabetes mellitus (T1DM) 6- to 12-year-old children in Riyadh, Kingdom of Saudi Arabia compared to non-diabetic children. Saudi Dent J. 2020.

[3]. Parameswaran A. Sturdevant's art and science of operative dentistry. J. Conserv. Dent. 2013 Sep 1;16(5):548.

[4]. Al-Malik MI, Rehbini YA. Prevalence of dental caries, severity, and pattern in age 6 to 7-year-old children in a selected community in Saudi Arabia. J Contemp Dent Pract. 2006 May 1;7(2):46-54.Pubmed PMID: 16685294.

[5]. Alotaibi F, Sher A, Khounganian R. Prevalence of early childhood caries among preschool children in Dawadmi, Saudi Arabia. IJMSCI. 2017;4:3010-4.

[6]. Martins MT, Sardenberg F, Vale MP, Paiva SM, Pordeus IA. Dental caries and social factors: impact on quality of life in Brazilian children. Braz Oral Res. 2015 Oct 9;29: S1806-83242015000100310.

[7]. Mhaske S, Yuwanati MB, Keswani H, Jain L. Evaluation of oral health awareness among public school children-A school-based study from Bhopal. Arch Med Health Sci. 2018 Jul 1;6(2):214.

[8]. Mishra A, Pandey RK, Chopra H, Arora V. Oral health awareness in schoolgoing children and its significance to parent's education level. J Indian Soc Pedod Prev Dent. 2018 Apr 1;36(2):120.

[9]. KANDHAN TS, JEEVANANDAN G. Oral Health Awareness Among School Going Children and Its Significance to Parents. Int. J. Pharm. Res. 2020 Jul;12(3).

[10]. Baliga S. A vision for pediatric and preventive dentistry oral health policy in India. J Indian Soc Pedod Prev Dent. 2018 Jul 1;36(3):223-4.

[11]. A, A A. Preventive Dentistry in Pediatric Oral Health - How Important Is It. Int. j. dent. sci. res. 2014;2.

[12]. Sánchez-Pérez L, Irigoyen-Camacho ME, Molina-Frechero N, Zepeda-Zepeda M. Fissure Depth and Caries Incidence in First Permanent Molars: A Five-Year Follow-Up Study in Schoolchildren. Int J Environ Res Public Health. 2019 Sep 23;16(19):3550.Pubmed PMID: 31547490.

[13]. Emmanuelli B, Knorst JK, Menegazzo GR, Mendes FM, Ardenghi TM. The Impact of Early Childhood Factors on Dental Caries Incidence in First Permanent Molars: A 7-Year Follow-Up Study. Caries Res. 2021;55(3):1-7. Pubmed PMID: 33789289.

[14]. Sanders BJ. Pit-and-Fissure Sealants and Preventive Resin Restorations. McDonald and Avery's Dentistry for the Child and Adolescent. 2016: 177-84.

[15]. Sanders BJ, Feigal RJ, Avery DR. Pit and Fissure Sealants and Preventive Resin Restorations. McDonald and Avery Dentistry for the Child and Ado- 
lescent. 2011: 313-21.

[16]. Yung KM. A retrospective study of preventive resin restorations. Degree Thesis of the University of Hong Kong .1994 Jan 1:1.

[17]. Murdoch-Kinch CA, McLEAN ME. Minimally invasive dentistry. J Am Dent Assoc. 2003 Jan 1;134(1):87-95.

[18]. Subramanyam D, Gurunathan D, Gaayathri R, Vishnu Priya V. Comparative evaluation of salivary malondialdehyde levels as a marker of lipid peroxidation in early childhood caries. Eur J Dent. 2018 Jan-Mar;12(1):67-70. Pubmed PMID: 29657527

[19]. Ramadurai N, Gurunathan D, Samuel AV, Subramanian E, Rodrigues SJ. Effectiveness of 2\% Articaine as an anesthetic agent in children: randomized controlled trial. Clin. Oral Investig. 2019 Sep;23(9):3543-50.

[20]. Ramakrishnan M, Dhanalakshmi R, Subramanian EMG. Survival rate of different fixed posterior space maintainers used in Paediatric Dentistry - A systematic review. Saudi Dent J. 2019 Apr;31(2):165-172.Pubmed PMID: 30983825.

[21]. Jeevanandan G, Thomas E. Volumetric analysis of hand, reciprocating and rotary instrumentation techniques in primary molars using spiral computed tomography: An in vitro comparative study. Eur J Dent. 2018 JanMar;12(1):21-26.Pubmed PMID: 29657521.

[22]. Princeton B, Santhakumar P, Prathap L. Awareness on Preventive Measures taken by Health Care Professionals Attending COVID-19 Patients among Dental Students. Eur J Dent. 2020 Dec;14(S 01):S105-S109.Pubmed PMID: 33321549

[23]. Saravanakumar K, Park S, Mariadoss AVA, Sathiyaseelan A, Veeraraghavan VP, Kim S, et al. Chemical composition, antioxidant, and anti-diabetic activities of ethyl acetate fraction of Stachys riederi var. japonica (Miq.) in streptozotocin-induced type 2 diabetic mice. Food Chem Toxicol. 2021 Sep;155:112374.Pubmed PMID: 34186120.

[24]. Wei W, Li R, Liu Q, Seshadri VD, Veeraraghavan VP, Mohan SK, et al. Amelioration of oxidative stress, inflammation and tumor promotion by Tin oxide-Sodium alginate-Polyethylene glycol-Allyl isothiocyanate nanocomposites on the 1, 2-Dimethylhydrazine induced colon carcinogenesis in rats. Arab. J. Chem. 2021 Jun 3;14(8):103238

[25]. Gothandam K, Ganesan VS, Ayyasamy T, Ramalingam S. Antioxidant potential of theaflavin ameliorates the activities of key enzymes of glucose metabolism in high fat diet and streptozotocin - induced diabetic rats. Redox Rep. 2019 Dec;24(1):41-50.Pubmed PMID: 31142215.

[26]. Su P, Veeraraghavan VP, Krishna Mohan S, Lu W. A ginger derivative, zingerone-a phenolic compound-induces ROS-mediated apoptosis in colon cancer cells (HCT-116). J Biochem Mol Toxicol. 2019 Dec;33(12):e22403. Pubmed PMID: 31714660.

[27]. Mathew MG, Samuel SR, Soni AJ, Roopa KB. Evaluation of adhesion of Streptococcus mutans, plaque accumulation on zirconia and stainless steel crowns, and surrounding gingival inflammation in primary molars: randomized controlled trial. Clin Oral Investig. 2020 Sep;24(9):3275-3280.Pubmed PMID: 31955271.

[28]. Sekar D, Johnson J, Biruntha M, Lakhmanan G, Gurunathan D, Ross K. Biological and clinical relevance of microRNAs in mitochondrial diseases/ dysfunctions. DNA Cell Biol. 2020 Aug 1;39(8):1379-84.

[29]. Velusamy R, Sakthinathan G, Vignesh R, Kumarasamy A, Sathishkumar D, Priya KN, et al. Tribological and thermal characterization of electron beam physical vapor deposited single layer thin film for TBC application. Surf Topogr: Metrol Prop. 2021 Jun 24;9(2):025043.

[30]. Aldhuwayhi S, Mallineni SK, Sakhamuri S, Thakare AA, Mallineni S, Sajja $\mathrm{R}$, et al. Covid-19 Knowledge and Perceptions Among Dental Specialists: A Cross-Sectional Online Questionnaire Survey. Risk Manag Healthc Policy. 2021 Jul 7;14:2851-2861.Pubmed PMID: 34262372.

[31]. Sekar D, Nallaswamy D, Lakshmanan G. Decoding the functional role of long noncoding RNAs (lncRNAs) in hypertension progression. Hypertens Res. 2020 Jul;43(7):724-725.Pubmed PMID: 32235913.

[32]. Bai L, Li J, Panagal M, M B, Sekar D. Methylation dependent microRNA 1285-5p and sterol carrier proteins 2 in type 2 diabetes mellitus. Artif Cells Nanomed Biotechnol. 2019 Dec;47(1):3417-3422.Pubmed PMID:
31407919.

[33]. Sekar D. Circular RNA: a new biomarker for different types of hypertension. Hypertens Res. 2019 Nov;42(11):1824-5.

[34]. Sekar D, Mani P, Biruntha M, Sivagurunathan P, Karthigeyan M. Dissecting the functional role of microRNA 21 in osteosarcoma. Cancer Gene Ther. 2019 Jul;26(7-8):179-182.Pubmed PMID: 30905966.

[35]. Duraisamy R, Krishnan CS, Ramasubramanian H, Sampathkumar J, Mariappan S, Navarasampatti Sivaprakasam A. Compatibility of Nonoriginal Abutments With Implants: Evaluation of Microgap at the Implant-Abutment Interface, With Original and Nonoriginal Abutments. Implant Dent. 2019 Jun;28(3):289-295.Pubmed PMID: 31124826.

[36]. Parimelazhagan R, Umapathy D, Sivakamasundari IR, Sethupathy S, Ali D, Kunka Mohanram R, et al. Association between Tumor Prognosis Marker Visfatin and Proinflammatory Cytokines in Hypertensive Patients. Biomed Res Int. 2021 Mar 16;2021:8568926.Pubmed PMID: 33816632.

[37]. Syed MH, Gnanakkan A, Pitchiah S. Exploration of acute toxicity, analgesic, anti-inflammatory, and anti-pyretic activities of the black tunicate, Phallusia nigra (Savigny, 1816) using mice model. Environ Sci Pollut Res Int. 2021 Feb;28(5):5809-5821.Pubmed PMID: 32978735.

[38]. Shah N. Dental caries: the disease and its clinical management. Br. Dent. J.. 2009 May;206(9):640

[39]. Poornima P, Disha P, Pai SM, Nagaveni NB, Roshan NM, Neena IE. Dental caries experience among 8-9-year-old school children in a South Indian City: A cross-sectional study.J. Indian Assoc. Public Health Dent. 2015 Apr $1 ; 13(2): 144$

[40]. Kiwanuka SN, Astrøm AN, Trovik TA. Dental caries experience and its relationship to social and behavioural factors among 3-5-year-old children in Uganda. Int J Paediatr Dent. 2004 Sep;14(5):336-46.Pubmed PMID: 15330999.

[41]. Blumer S, Peretz B, Ratson T. The use of restorative materials in primary molars among pediatric dentists in Israel. J. Clin. Pediatr. Dent. 2017;41(3): 424-8.

[42]. Asnani K. Pit and fissure sealants and conservative Adhesive Restoration. Essentials of Pediatric Dentistry. 2010:147.

[43]. Ripa LW, Wolff MS. Preventive resin restorations: indications, technique, and success. Quintessence Int. 1992 May 1;23(5) :307-15.

[44]. Dhar V, Bhatnagar M. Dental caries and treatment needs of children (6-10 years) in rural Udaipur, Rajasthan. Indian J Dent Res. 2009 JulSep;20(3):256-60.Pubmed PMID: 19884704.

[45]. Chankanka O, Marshall TA, Levy SM, Cavanaugh JE, Warren JJ, Broffitt B, et al. Mixed dentition cavitated caries incidence and dietary intake frequencies. Pediatr Dent. 2011 May-Jun;33(3):233-40.Pubmed PMID: 21703076.

[46]. Demirci M, Tuncer S, Yuceokur AA. Prevalence of caries on individual tooth surfaces and its distribution by age and gender in university clinic patients. Eur. J. Dent. 2010 Jul;4(03):270-9.

[47]. Lakshmanan L, Ravindran V, Ravindran V, Subramanian EM. Utilization of Sealants and Conservative Adhesive Resin Restoration for Caries Prevention by Dental Students. Indian J. Forensic Med. Toxicol. 2020 Oct $1 ; 14(4): 5865$

[48]. Luan W, Baelum V, Fejerskov O, Chen X. Ten-year incidence of dental caries in adult and elderly Chinese. Caries Res. 2000 May-Jun;34(3):205-13. Pubmed PMID: 10867418.

[49]. Macek MD, Beltrán-Aguilar ED, Lockwood SA, Malvitz DM. Updated comparison of the caries susceptibility of various morphological types of permanent teeth. J Public Health Dent. 2003 Summer;63(3):174-82.Pubmed PMID: 12962471.

[50]. Antunes JL, Junqueira SR, Frazão P, Bispo CM, Pegoretti T, Narvai PC. City-level gender differentials in the prevalence of dental caries and restorative dental treatment. Health Place. 2003 Sep;9(3):231-9.Pubmed PMID: 12810330 .

[51]. Manji F, Baelum V, Fejerskov O. Tooth mortality in an adult rural population in Kenya. J Dent Res. 1988 Feb;67(2):496-500 